\title{
Performance Analysis of Multi Converter Unified Power Quality Conditioner with Dual Feeder System using Fuzzy Logic Control
}

\author{
${ }^{1}$ G. B.Mohankumar and ${ }^{2}$ S.Manoharan \\ 1. Associate Professor, Department of EIE, Nandha Engineering College \\ (Autonomous), Erode, Tamil Nadu, India \\ 2. Professor \&Head Department of EIE, Karpagam College of \\ Engineering(Autonomous), Coimbatore, Tamil Nadu, India \\ 1.gbmohankumar@nandhaengg.org \\ 2.manoish07@gmail.com
}

\begin{abstract}
Many customers who require high reliable power, utilities provide dual feeds; i.e. service to a facility comes from two independent transmission lines. Maintaining power quality is an important issue in the transmission and sub transmission system. Unified Power Quality Conditioner is the optimal solution to ameliorate the quality of power. Many researchers analyzed the performance of UPQC with various control techniques. Recent advanced UPQC is the Multi Converter Unified Power Quality Conditioner (MC$U P Q C)$. Conventionally the MC-UPQC is controlled using the PI controller for DC link voltage control. This paper proposes Fuzzy Logic Controller (FLC) to enhance the performance of the MC-UPQC to improve the power quality in a multi bus with sub transmission system. In this article MC-UPQC is designed with two series and one shunt voltage-source converters (VSC). It is nominated to follow out in adjacent transmission lines to improve the quality of electric potential. In the proposed system, all converters are connected back to back on the dc side and share a common DC-link capacitor. It results in the transfer of power from one line to adjacent line to compensate for voltage sag/swell. Performance of MC-UPQC using the conventional PI controller and proposed FLC are compared. Harmonics produced by voltage distortion is also reduced within IEEE standards. The whole system is simulated and analyzed using MATLAB7.7/ Simulink.
\end{abstract}

Keywords: Power Quality (PQ), Multi Converter Unified Power Quality Conditioner (MC-UPQC), Voltage-Source Converter (VSC), Transmission Line, Fuzzy logic controller, PI controller, Deregulation

\section{Introduction}

Increase in power electronics devices increases harmonics in the system and it requires high quality power for its effective and efficient control. In case of three phase system these devices produce unbalanced load in many cases. With the ever increasing complexities in power systems across the globe and growing need to provide stable, secure, controlled, economical, and high-quality power-especially in the deregulated environment, it is envisaged that FACTS controllers will play a critical role in power systems in the future. The increase in the use of Power Quality (PQ) sensitive equipment, increased use of equipment that generates power quality problems, and deregulation of the 
power industry are the factors which influence the utilities and their customer's competitiveness. As the need for reliable and efficient electrical power system increases, the utility transmission and distribution system increased in complexity and the voltage. Therefore, the utilities and their customers need prompt and immediate information about power quality at the transmission, distribution and end-user levels. Thus, power quality systems become more complex.

Unified Power Quality Conditioner (UPQC) has become very popular in recent years, both in low voltage and medium voltage applications. Most of the proposed and practiced control strategies for power quality conditioners have been reviewed with regard to performance and implementation. UPQC systems were studied by many researchers as an eventual method to improve the PQ in electrical distribution systems [1].

Hideaki Fujita et al. [5] analyzed the Integration of Series and Shunt Active Filters for a Unified Power Quality Conditioner. Vadirajacharya G et al. [17], studied the performance of Neural Network Based Unified Power-Quality Conditioner using PI controller. Mauricio Aredes et al. [3] proposed a Universal Active Power Line Conditioner that incorporates not only the compensation functions at the fundamental frequency like a Unified Power Flow Controller (UPFC), but also provides active harmonic mitigation capabilities. Amit Kumar Jindal et al. [2] gave an idea about Interline Unified Power Quality Conditioner using a voltage source converter, to improve the power quality of two feeders in a distribution system. B. Han et al. [9] deliberated the Operation of Unified Power-Quality Conditioner with Distributed Generation using unified power-quality conditioner. Mehdi Forghani et al. [13] anticipated the control strategy for UPQC Control System using online wavelet transform. Sudipta Chakra borty et al. [16] explore the Experimental Evaluation of Active Filtering in a Single-Phase High-Frequency AC Micro grid using unified power quality conditioner to control the power flow and power quality, respectively. Vinod Khadkikar [18] analyzed the various types of UPQC for enhancing the power quality.

It is observed that many PQ issues have originated in transmission and distribution network and also important that the utilities recognize the need to overcome PQ issues by upgrading the network with available technology interventions and practices. Many researchers were analyzed the performance of UPQC in a secondary power distribution system. Apparently there are no analyses of UPQC in a sub transmission system to improve the quality of power in primary power distribution substations. The role of sub transmission system is mainly the same as that of the primary power distribution system, except that it serves a larger geographical area and distributes larger block of energy at higher voltage levels. It may be noted that there is no clear demarcation line between transmission and sub-transmission voltage levels. The sub transmission lines distribute the transmitted energy to a number of primary power distribution substations in a certain geographical location.

A new configuration of a UPQC called the Multi Converter Unified Power Quality Conditioner (MC-UPQC) using the PI controller in sub transmission system with primary power distribution substations at the end of the line is analyzed by Mohankumar. G. B and S. Manoharan [14]. The system is extended by adding a series-VSC in an adjacent bus. The proposed topology can be used for simultaneous compensation of voltage and current imperfections in both buses by sharing power compensation capabilities between two adjacent buses which are not connected. The system is also capable of compensating for interruptions without the need for a battery storage system and consequently without storage capacity limitations. Since it has a PI controller for DC link voltage regulation, it 
has to be enhanced in the case of transient states. Therefore, in this paper PI controller and Fuzzy Logic Controller are proposed for enhancing the performance of MC UPQC.

\section{Proposed MC-UPQC System}

\subsection{Circuit Configuration}

For many customers or loads that require highly reliable power, then the utilities provide dual feeds; i.e. service to a load comes from two independent transmission lines. Two transmission lines are connected to two different generating stations that supplies lumped primary power distribution substation L1 and L2 are considered in the analysis of MC-UPQC. The primary power distribution substation is considered as a load for sub transmission line. The single-line diagram of a sub transmission system with an MCUPQC is shown in Figure 1.

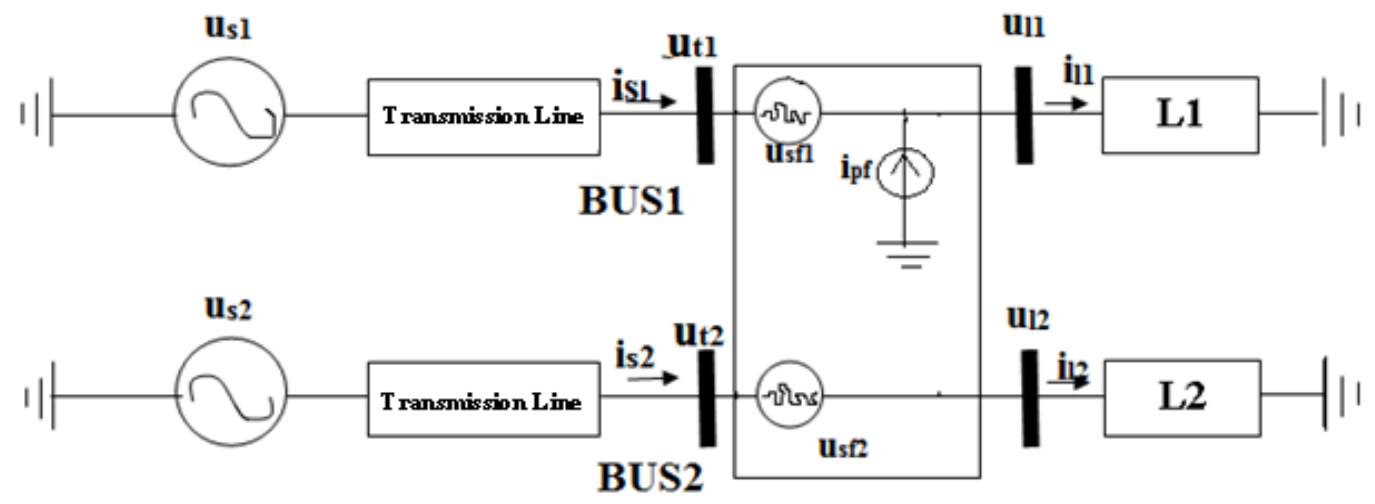

Figure 1. Single-line Diagram of a Sub Transmission System with an MCUPQC

The MC-UPQC is connected with two buses BUS1 and BUS2 with voltages of $\mathrm{u}_{\mathrm{t} 1}$ and $\mathrm{u}_{\mathrm{t} 2}$, respectively. $\mathrm{U}_{\mathrm{s} 1}$ and $\mathrm{u}_{\mathrm{s} 2}$ are supplied voltages and $\mathrm{u}_{11}$ and $\mathrm{u}_{12}$ are load voltages. Finally, sub transmission line currents are denoted by $i_{s 1}$ and $i_{s 2}$, load currents are $i_{11}$ and ${ }_{12}$. The shunt part of the MC-UPQC is also connected to L1 with a current of $i_{11}$.

Various types of Loads such as sensitive, critical, linear and nonlinear are supplied by the power system. Bus voltages $\mathrm{u}_{\mathrm{t} 1}$ and $\mathrm{u}_{\mathrm{t} 2}$ are distorted and may be subject to sag/swell. Loads may produce harmonics in system current. Sensitive [19] and critical loads need pure sinusoidal and distortion free voltage. It necessitates the MC-UPQC in a sub transmission system.

\subsection{MC-UPQC Structure}

The internal structure of the MC-UPQC is shown in Figure. 2. It consists of three VSCs (VSC1, VSC2, and VSC3) which are connected back to back through a common DC-link Capacitor $\left(\mathrm{C}_{\mathrm{dc}}\right)$. In the proposed configuration, VSC1 is connected in series with BUS1 and VSC2 is connected in parallel with the primary power distribution substation $\mathrm{L} 1$ at the end of sub transmission line1. VSC3 is connected in series with BUS2 at the sub transmission line 2 end. 


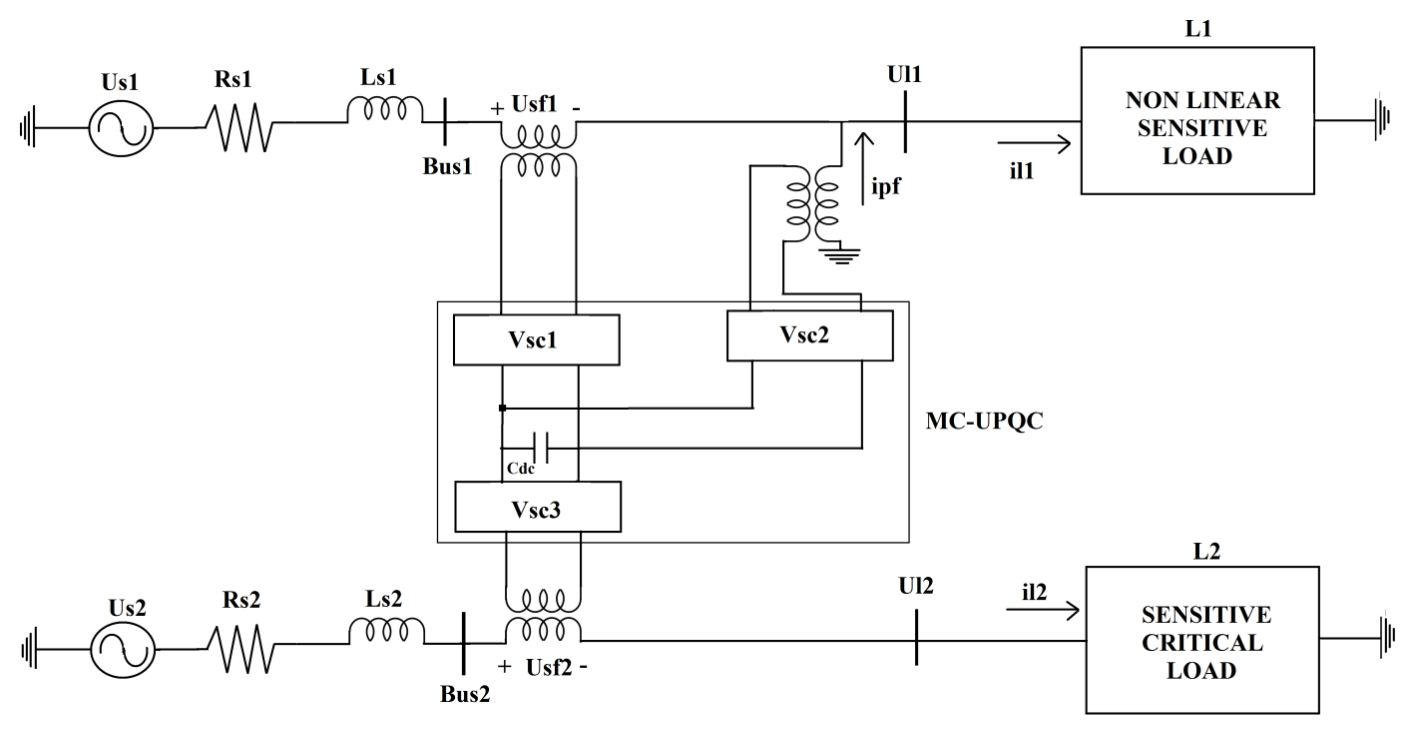

Figure 2. Typical MC-UPQC used in a Primary Power Distribution System

Common DC-link capacitor supplies all converters and connects the sub transmission system through a transformer. The series-connected transformers secondary sides are directly [7] connected in series with BUS1 and BUS2, and the shunt-connected transformer secondary side is connected in parallel with primary distribution substation L1. The MC-UPQC is intended:

1) To regulate the load voltage $\left(\mathrm{V}_{11}\right)$ against sag/swell in the system to protect the nonlinear/sensitive load of primary power distribution substation L1;

2) To regulate the load voltage $\left(\mathrm{V}_{12}\right)$ against sag/swelling the system to protect the sensitive/ critical load of primary power distribution substation L2;

3) To compensate for the reactive and harmonic components of nonlinear load current $i_{11}$

In order to achieve these goals, series VSCs (i.e., VSC1 and VSC3) operate as voltage controllers while the shunt VSC (i.e., VSC2) operates as a current controller.

All VSCs consist of a three-phase converter with a commutation reactor and high-pass output filter $[6,8]$ to avert the flow of switching harmonics into the power supply the commutation reactor and high pass output filter is connected.

\subsection{Control Strategy}

All VSCs are controlled independently using sinusoidal pulse width-modulation (SPWM) voltage control and hysteresis current control [8].

Shunt-VSC: The functions of the shunt-VSC are:

1) To compensate for the reactive component of primary power distribution substation load current $\mathrm{i}_{11}$

2) To compensate for the harmonic components of primary power distribution substation load current $\mathrm{i}_{12}$

3) To regulate the voltage of the common DC-link capacitor.

The measured load current $\left(i_{1-a b c}\right)$ is transformed $[8,10]$ into the synchronous dqo reference frame by using 


$$
\begin{aligned}
& i_{1-q}=2 / 3\left[i_{1 a} \cos \theta+i_{1 b} \cos (\theta-2 \pi / 3)+i_{1 c} \cos (\theta+2 \pi / 3)\right] \\
& i_{1-d}=2 / 3\left[i_{1 a} \sin \theta+i_{1 b} \sin (\theta-2 \pi / 3)+i_{1 c} \sin (\theta+2 \pi / 3)\right] \\
& i_{1-0}=1 / 3\left[i_{1 a}+i_{1 b}+i_{1 c}\right]
\end{aligned}
$$

By this transform all harmonic components are transformed into a quantity with a fundamental frequency shift. Low-pass filters (LPFs) extracts the DC quantities in the d and $\mathrm{q}$ axes from the fundamental positive-sequence component.

$\mathbb{1}_{1-d}=\mathbb{n}_{1-d}+\tilde{I}_{1-d}$

$\mathrm{I}_{1-\mathrm{q}}=\mathrm{I}_{1-\mathrm{q}}+\mathrm{I}_{1-q}$

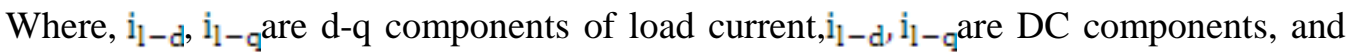
$\tilde{I}_{1-d, I_{1}-q}$ are the AC components of $\mathbb{1}_{1-d}$ andi ${ }_{1-q}$.

Let us assumei $i_{a}=i_{l s h}$, where $i_{\Omega}$ the feeder is current and $i_{s h}$ is the shunt VSC current. Then $\mathrm{d}-\mathrm{q}$ components of the shunt VSC reference current are defined as follows:

$$
\begin{aligned}
& \mathrm{I}_{\mathrm{pf}}^{\mathrm{ref}} \mathrm{d}=\mathrm{I}_{\mathrm{l}-\mathrm{d}} \\
& \mathrm{i}_{\mathrm{pf}-\mathrm{q}}^{\mathrm{ref}}=\mathrm{I}_{\mathrm{l}-\mathrm{q}}
\end{aligned}
$$

Consequently, the $\mathrm{d}-\mathrm{q}$ components of the base current are

$\mathrm{i}_{\mathrm{g}-\mathrm{d}}=\mathrm{i}_{1-\mathrm{d}}$

$\mathrm{i}_{\mathrm{s}-\mathrm{q}}=0$

Equation (8) and (9) specify that harmonic and reactive components free sub transmission line current. In this paper a Proportional-Integral (PI) controller [15] is proposed to regulate DC link voltage disturbed by switching losses and sudden changes in load. The control block diagram of shunt VSC is shown in Figure 3. The error between the actual capacitor voltage $\left(\mathrm{V}_{\mathrm{dc}}\right)$ and its reference value $\mathrm{V}_{\mathrm{dc}}^{\text {ref }}$ is processed by PI controller and produces $\Delta_{\mathrm{idc}}$. The output of the PI controller is added to the component of the shuntVSC reference current to form a new reference current as follows

$\left\{\begin{array}{c}i_{p f-d}^{\text {ref }}=\tilde{1}_{1-d}+\Delta_{i d c} \\ 1_{p f-q}=i_{1-q}\end{array}\right.$ 


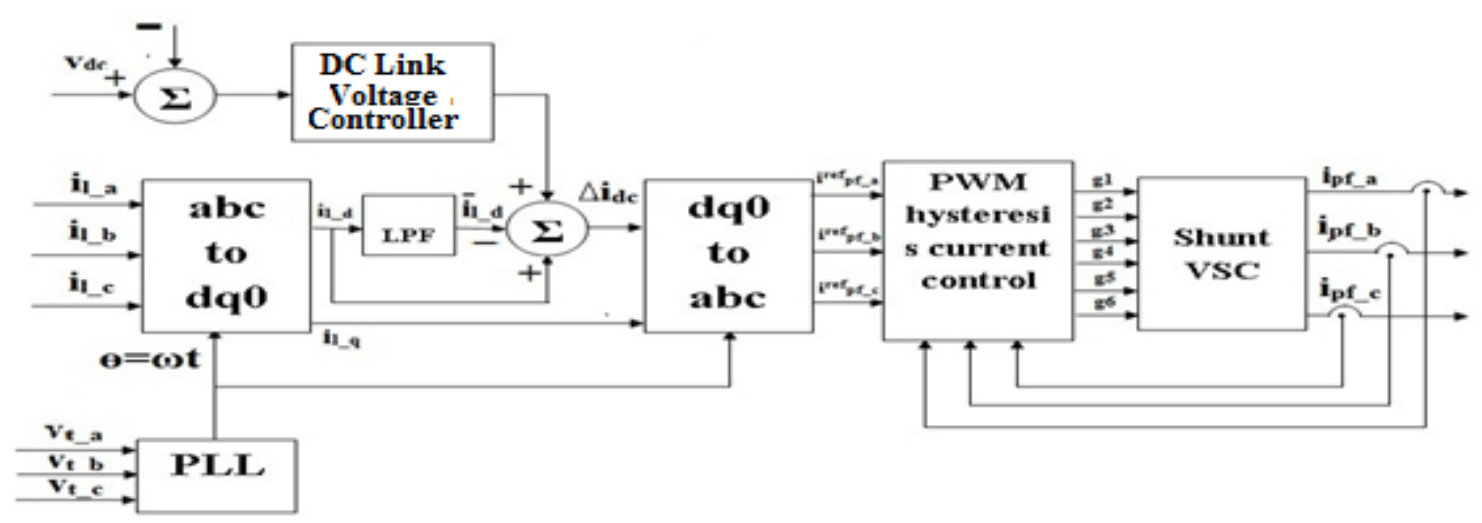

Figure 3. Control Block Diagram of the Shunt VSC

Then Inverse park transformation [12] is applied to the reference current. By using PWM hysteresis current control, the output-compensating currents in each phase are obtained

$$
\begin{aligned}
& \mathrm{i}_{\mathrm{pf}-\mathrm{a}}^{\mathrm{ref}}=\mathrm{i}_{\mathrm{pf}-\mathrm{q}}^{\mathrm{ref}} \cos \theta+\mathrm{i}_{\mathrm{pf}-\mathrm{d}}^{\mathrm{ref}} \sin \theta \\
& i_{p f-b}^{r e f}=i_{p f-q}^{r e f} \cos (\theta-2 \pi / 3)+i_{p f-d}^{r e f} \sin (\theta-2 \pi / 3) \\
& \mathrm{i}_{\mathrm{pf}-\mathrm{c}}^{\mathrm{ref}}=\mathrm{i}_{\mathrm{pf}-\mathrm{q}}^{\mathrm{ref}} \cos (\theta+2 \pi / 3)+\mathrm{i}_{\mathrm{pf}-\mathrm{d}}^{\mathrm{ref}} \sin (\theta+2 \pi / 3)
\end{aligned}
$$

Series-VSC: The functions of the series VSCs in each sub transmission lines are:

1) To lessen voltage sag and swell;

2) To compensate voltage distortions, such as harmonics;

3) To compensate for interruptions (in Bus2 only).

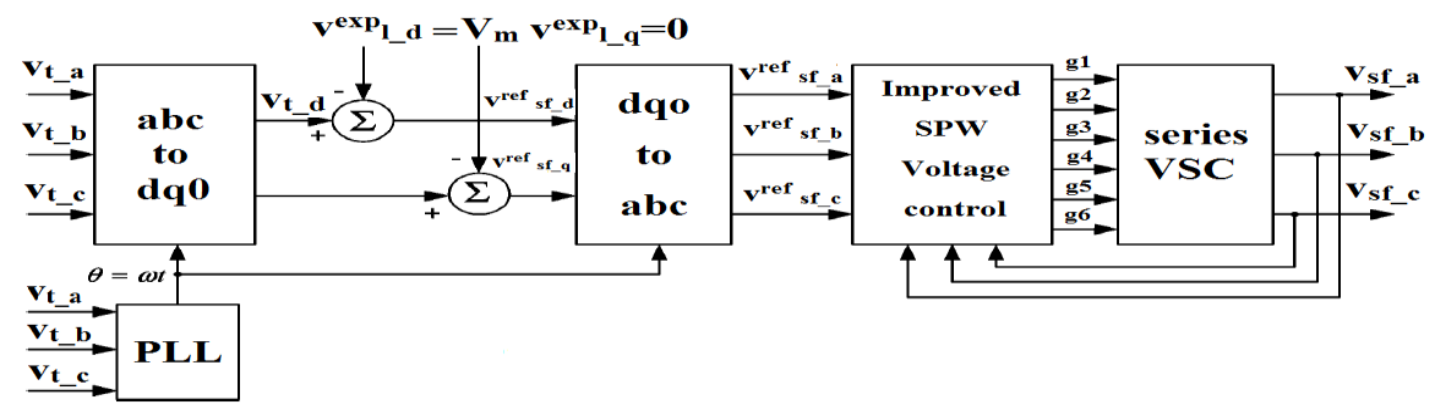

Figure 4. Control Block Diagram of the Series VSC

The control block diagram of each series VSC is shown in Figure 4. The bus voltage is detected and then transformed into the synchronous reference frame using

$V_{t-d q o}=T_{a b c}^{d q o} V_{t-a b c}=V_{t 1 p}+V_{t 1 n}+V_{t 10}+V_{t h}$

Where 


$$
\begin{aligned}
& V_{t 1 p}=\left[V_{t 1 p-d} V_{t 1 p-q} \circ\right] T \\
& \mathrm{~V}_{\mathrm{t} 1 \mathrm{n}}=\left[\mathrm{V}_{\mathrm{t} 1 \mathrm{n}-\mathrm{d}} \mathrm{V}_{\mathrm{t} 1 \mathrm{n}-\mathrm{q}} \mathrm{o}\right] \mathrm{T} \\
& \mathrm{V}_{\mathrm{t} 10}=\left[\begin{array}{lll}
0 & 0 & \mathrm{~V}_{00}
\end{array}\right] \mathrm{T} \\
& \mathrm{V}_{\text {th }}=\left[\mathrm{V}_{\text {th }-\mathrm{d}} \mathrm{V}_{\text {th }-\mathrm{q}} \mathrm{V}_{\text {th }-0}\right] \mathrm{T}
\end{aligned}
$$

$V_{t 1 p}, V_{t 1 n} A n d V_{t 10}$ are the fundamental frequency positive, negative and zero sequence components, respectively and $\mathrm{u}_{\mathrm{th}} \mathrm{is}$ the harmonic component of the bus voltage.

Therefore, the load voltage in the synchronous dqo reference frame $\left(V_{1-\text { dq }}^{\exp }\right)$ has to follow (19) to keep the load voltage be sinusoidal with constant amplitude even if the bus voltage is disturbed.

$$
\mathrm{V}_{\mathrm{t}-\mathrm{dqo}}^{\exp }=\mathrm{T}_{\mathrm{abc}}^{\mathrm{dqo}} \mathrm{V}_{1-\mathrm{abc}}^{\exp }=\underset{0}{0}
$$

Where the load voltage in the abc reference frame $\left(V_{t-a b c}^{\exp }\right)$ is

$$
\mathrm{V}_{\mathrm{m}} \cos (\mathrm{wt})
$$

$$
\begin{aligned}
V_{1-a b c}^{e x p}= & V_{m} \cos \left(w t-120^{2}\right) \\
& V_{m} \cos \left(w t+120^{2}\right)
\end{aligned}
$$

The compensating reference voltage in the synchronous dqo reference frame $V_{\mathrm{gf}}^{\mathrm{ref}}$ dqo is defined as

$\mathrm{Vu}_{\mathrm{gf}}^{\mathrm{ref}} \mathrm{dqo}=\mathrm{V}_{\mathrm{t}-\mathrm{dqo}}-\mathrm{V}_{1-\mathrm{dqo}}^{\mathrm{exp}}$

This means $V_{\mathrm{t} 1 \mathrm{p}-\mathrm{d}}$ in (15) should be maintained at $\mathrm{V}_{\mathrm{m}}$ while all other unwanted components must be eliminated. The compensating reference voltage in (20) is then transformed back into the abc reference frame. By using a PWM voltage control technique, the output compensation voltage of the series VSC can be obtained.

\section{DC Link Voltage Controller}

DC link voltage controller is an important controller to produce id reference current. In this paper, PID controller and Fuzzy Logic Controller are proposed to control DC link voltage. The performance of the FLC is compared with the conventional PI and PID controller. The PI controller is the widely recognized for controlling converters due to its relatively simple structure. The traditional PI controller, however, is based on an accurate model of linear control, where the preprogrammed sets are unable to automatically adapt to the nonlinearity by a sudden change in load. It necessitates a controller to produce reference current with respect to changes in voltage.

\subsection{PI controller}


The Proportional Integral controller is the widely recognized for controlling converters due to its relatively simple structure. Still, it is the most common form of controller among various converters and motor servo systems. In this paper error between actual capacitor voltage and reference capacitor voltage is given as input to PI controller and output is taken into the system. The mathematical expression of PI controller is

$\mathrm{U}(\mathrm{s})=\mathrm{K}_{\mathrm{p}} \mathrm{E}(\mathrm{s})+\frac{\mathrm{K}_{\mathrm{i}}}{\mathrm{s}} \mathrm{E}(\mathrm{s})$

The proportional and the integral gain are represented as $\mathrm{K}_{\mathrm{P}}$ and $\mathrm{K}_{\mathrm{i}}$. Whereas input and output of the controller are $\mathrm{E}(\mathrm{s})$ and $\mathrm{U}(\mathrm{s})$. The lack of derivative action may make the system steadier in the steady state in the case of noisy data. This is because derivative action is more sensitive to higher-frequency terms in the inputs. Figure 5 shows the block diagram of PI controller.

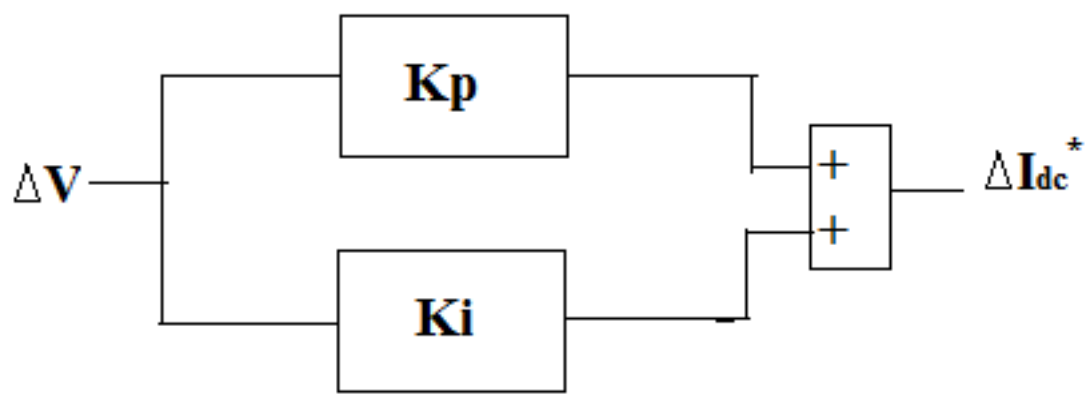

Figure 5. PI Controller

Ziegler Nichols' method of tuning is adopted to find the optimum value of $K_{\mathrm{P}} \& \mathrm{~K}_{\mathrm{i}}$ values. It reduces steady state error and settling time. The traditional PID controller, however, is based on an accurate model of linear control, where the preprogrammed sets are unable to automatically adapt to the nonlinearity by a sudden change in load. It necessitates a controller to produce reference current with respect to changes in voltage.

\subsection{PID Controller}

A Proportional-Integral-Derivative controller (PID controller) is a feedback controller, widely used in industrial control systems. A PID controller calculates an error value as the difference between a measured process variable and a desired set point. The PID controller calculation involves three separate constant parameters, and is sometimes called three-term controller: proportional, integral and derivative values, denoted P, I, and D. By tuning the three parameters in the PID controller, the controller can provide control action designed for specific process requirements. The transfer function of a standard PID controller in an ideal form is (Kuldeep Kumar Singh\& J. K Dwivedi, 2012)

$\mathrm{G}(\mathrm{S})=\mathrm{K}_{\mathrm{p}}+\mathrm{K}_{\mathrm{i}}(1 / \mathrm{S})+\mathrm{K}_{\mathrm{d}} \mathrm{S}$

Where $\mathrm{K}_{\mathrm{d}}$ is the derivative gain. In the PID controller, the three parameters $\mathrm{K}_{\mathrm{p}}$, Ki and $\mathrm{K}_{\mathrm{d}}$ have different effect on the quality of power. 
Typical steps for designing a PID controller have determined the characteristics of the system which needs to be improved, Use $K_{P}$ to decrease the rise time, Use $K_{d}$ to reduce the overshoot and settling time and $U$ se $\mathrm{K}_{\mathrm{i}}$ to eliminate the steady-state error.

\subsection{Fuzzy Logic Controller}

To produce id reference in a non-linearity Fuzzy logic controller is proposed in this paper. Fuzzy logic is the mathematical technique for dealing with imprecise data and problems have multiple solutions rather than one. Linguistic, non-numerical, variables are used, making it similar to the way humans think. Fuzzy control methodology is considered as an effective method to deal with disturbances and uncertainties in terms of ambiguity. In this paper Fuzzy Logic Controller (FLC) is implemented to reduce overshoot and settling time. Figure 6 shows the basic block diagram of fuzzy logic controller [16].

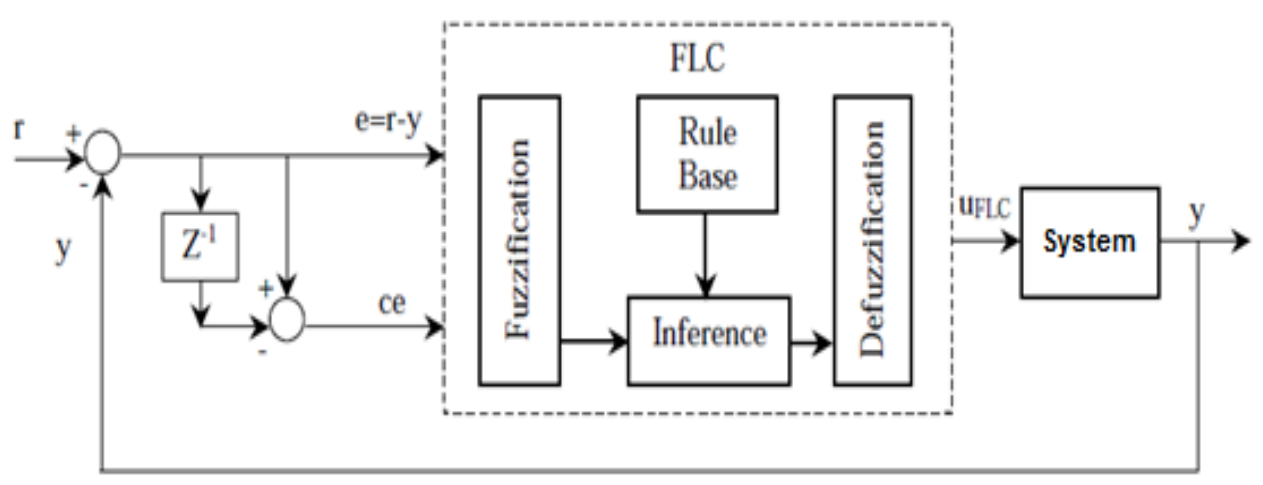

Figure 6. Fuzzy Logic Controller

Fuzzy inference system is the overall name for a system that uses fuzzy reasoning to map an input space to an output space. There are several ways to define the result of a rule; this paper implies max-min method of inference. Here, Mamdani type of fuzzy has been implemented. It has two inputs such as DC link voltage error (e) as (23), change in error (ce) and one output $\Delta \mathrm{i}_{\mathrm{dc}}$.

$$
\mathrm{E}=\mathrm{V}_{\mathrm{dc}}^{8}-\mathrm{V}_{\mathrm{dc}}
$$

Both inputs and output have five membership functions such as NB-negative big, NSnegative small, $\mathrm{Z}$-zero, PS-Positive Small and PB-Positive Big. IF THEN based rules are formed using membership functions such as

1. If error is Negative Big and change in error is Negative Big then change in $i_{\mathrm{dc}}$ is Negative Big.

2. If error is Negative Big and change in error is Negative Small then change in $i_{d c}$ is Negative Small.

3. If error is Negative Big and change in error is Zero then change in $i_{\mathrm{dc}}$ is Negative Small.

Defuzzification is the mathematical procedure to convert fuzzy values into crisp values. Many methods of defuzzification are available. In this study we have selected 
centroid method of defuzzification. Table 1 shows the fuzzy rules. Figure 7 shows the membership functions of inputs and output.

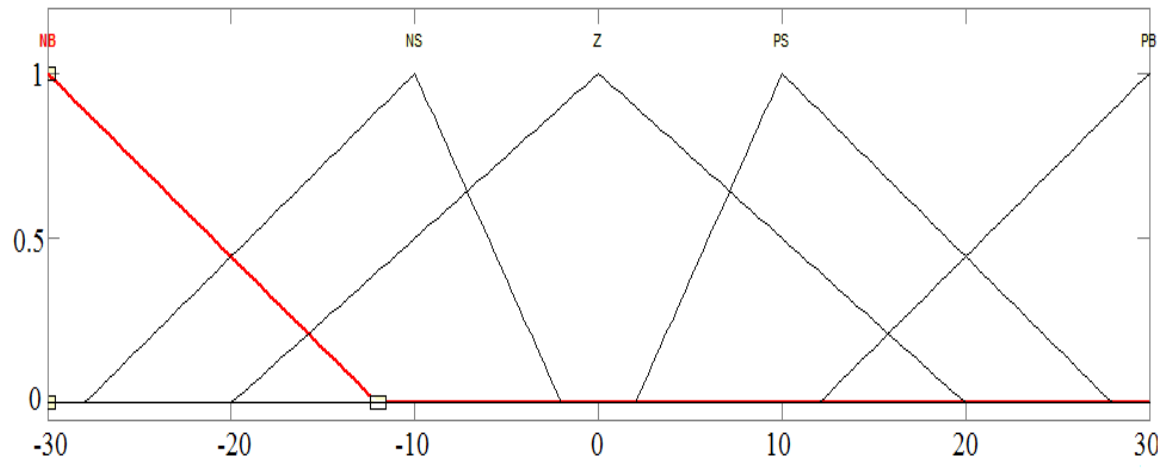

Figure 7. Membership Functions of e, ec and $\Delta \mathbf{i}_{d c}$

Table 1. Fuzzy Rules

\begin{tabular}{|c|c|c|c|c|c|}
\hline ec & \multirow{2}{*}{ NB } & \multirow{2}{*}{ NS } & \multirow{2}{*}{$\mathbf{Z}$} & \multirow{2}{*}{ PS } & \multirow{2}{*}{ PB } \\
\hline e & & & & & \\
\hline $\mathbf{N B}$ & NB & $\mathrm{NS}$ & NS & $\mathrm{Z}$ & PS \\
\hline $\mathbf{N S}$ & NB & $\mathrm{NS}$ & NS & PS & PB \\
\hline $\mathbf{Z}$ & NB & $\mathrm{NS}$ & $\mathrm{Z}$ & PS & PB \\
\hline PS & NB & NS & PS & PS & PB \\
\hline PB & NS & $\mathrm{Z}$ & PS & PS & PB \\
\hline
\end{tabular}

FLC produces reference id current optimally in case of steady state as well as in dynamic state that is in a linear and nonlinear system it controls well.

\section{Power Rating Analysis of the MC-UPQC}

The cost of the MC-UPQC mainly depends on the power rating [8]. To find the minimum power rating of each VSC in the MC UPQC structure, two models for UPQC quadrature compensation (UPQC-Q) and in phase compensation (UPQC-P) are analyzed and the best model which requires the minimum power rating is considered. In the UPQC-Q compensation scheme, the injected voltage by the series VSC maintains a quadrature advance relationship with the supply current so that no real power is consumed by the series VSC at steady state. This is a significant advantage when UPQC mitigates sag conditions. The series VSC also shares the volt ampere reactive (VAR) of the load along with the shunt-VSC, reducing the power rating of the shunt-VSC.

The comparison between in phase (UPQC-P) and quadrature (UPQC-Q) models is made for different sag conditions and load power factors [4]. If quadrature compensation in sub transmission line 1 and in phase compensation in sub transmission line 2 is selected, then the power rating of the shunt VSC and the series VSC (in sub transmission line 2) will be reduced. This is an important criterion for practical applications. 


\section{Simulation Results and Discussion}

The whole system is simulated and analyzed using MALAB7.7/Simulink. The sudden changes in load causes voltage sag or swell. The MC-UPQC system parameters used in this study are given in Table 2.

Table 2. MC-UPQC Experimental and Simulation Parameters

\begin{tabular}{|l|l|l|}
\hline Source & Parameters & Value \\
\hline $\begin{array}{l}\text { Sub Transmission } \\
\text { Line }\end{array}$ & Voltage & $110 \mathrm{kV}$ \\
\hline $\begin{array}{l}\text { Primary Power } \\
\text { Distribution Sub } \\
\text { Station }\end{array}$ & Voltage & $110 \mathrm{kV} / 11 \mathrm{kV}$ \\
\hline $\begin{array}{l}\text { Secondary Power } \\
\text { Distribution Sub } \\
\text { Station }\end{array}$ & Voltage & \\
\hline & & $11 \mathrm{kV} / 400 \mathrm{~V} / 230 \mathrm{~V}$ \\
\hline \multirow{3}{*}{$\begin{array}{l}\text { Shunt Active Power } \\
\text { Filter }\end{array}$} & Frequency & \\
\cline { 2 - 3 } & Filter capacitor & $50 \mathrm{~Hz}$ \\
\cline { 2 - 3 } $\begin{array}{l}\text { Series Active Power } \\
\text { Filter }\end{array}$ & Line inductor & $1 \Omega$ \\
\cline { 2 - 3 } & Filter Resistor & $10 \mu \mathrm{F}$ \\
\cline { 2 - 3 } DC Link & Line inductor & $1 \Omega .15 \mathrm{mH}$ \\
\hline
\end{tabular}

The simulation model of MC-UPQC is shown in Figure 8.

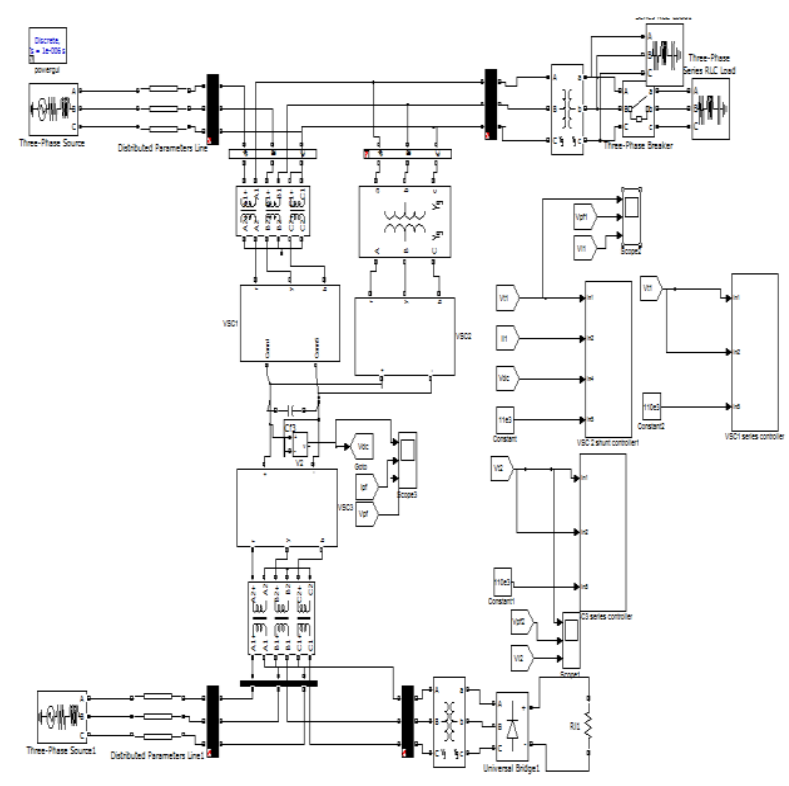

Figure 8. Simulation Model of MC-UPQC 
International Journal of Control and Automation

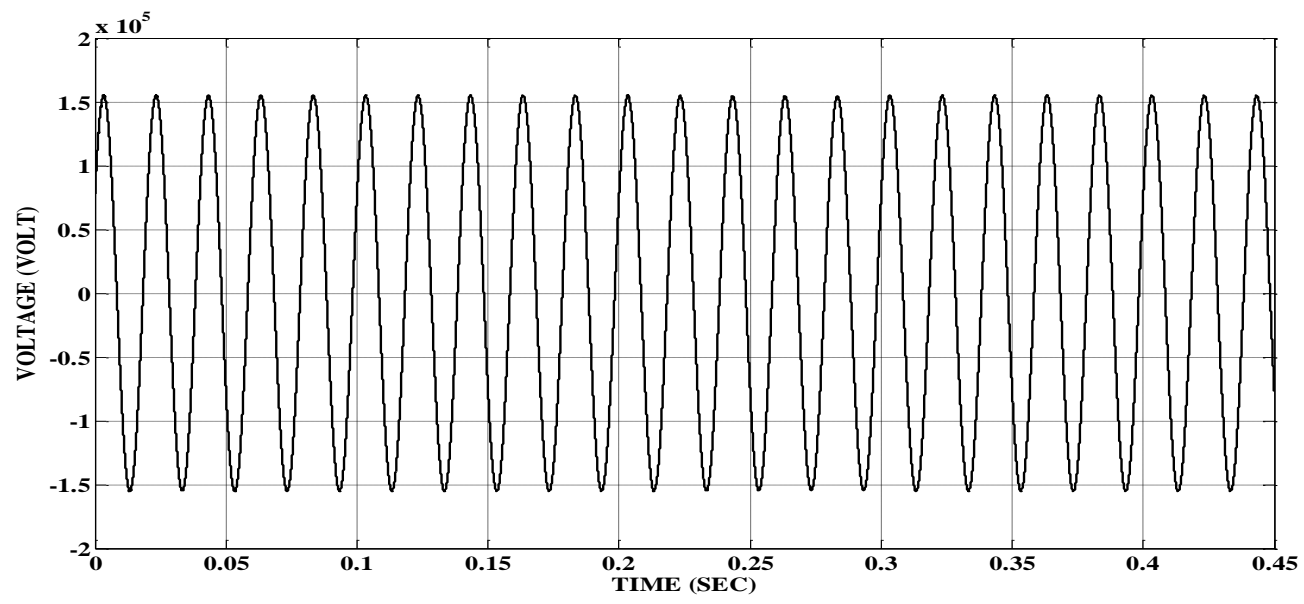

Figure 9.a. The Source Voltage

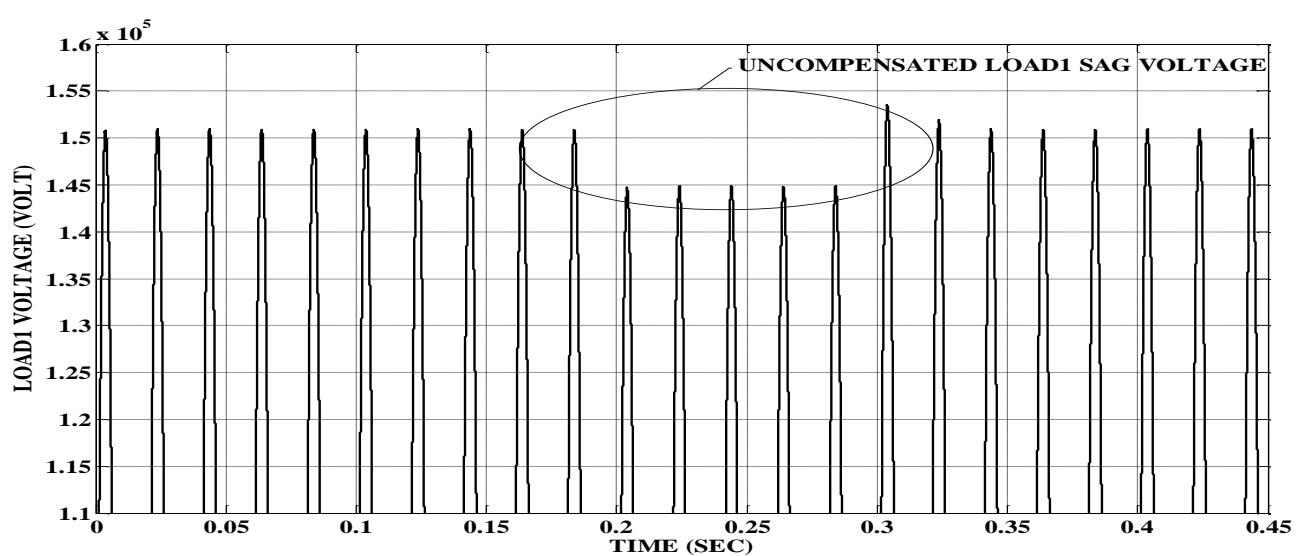

Figure 9.b. Uncompensated Load1 Voltage

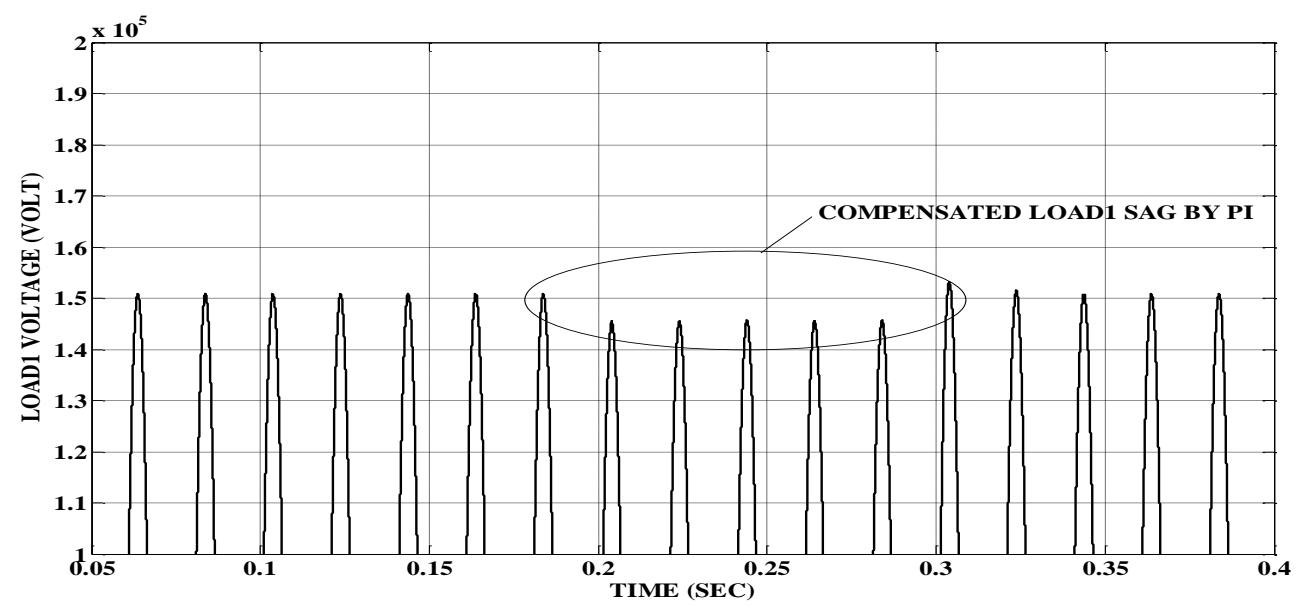

Figure 9.c. Compensated Load1 Voltage using PI Controller 


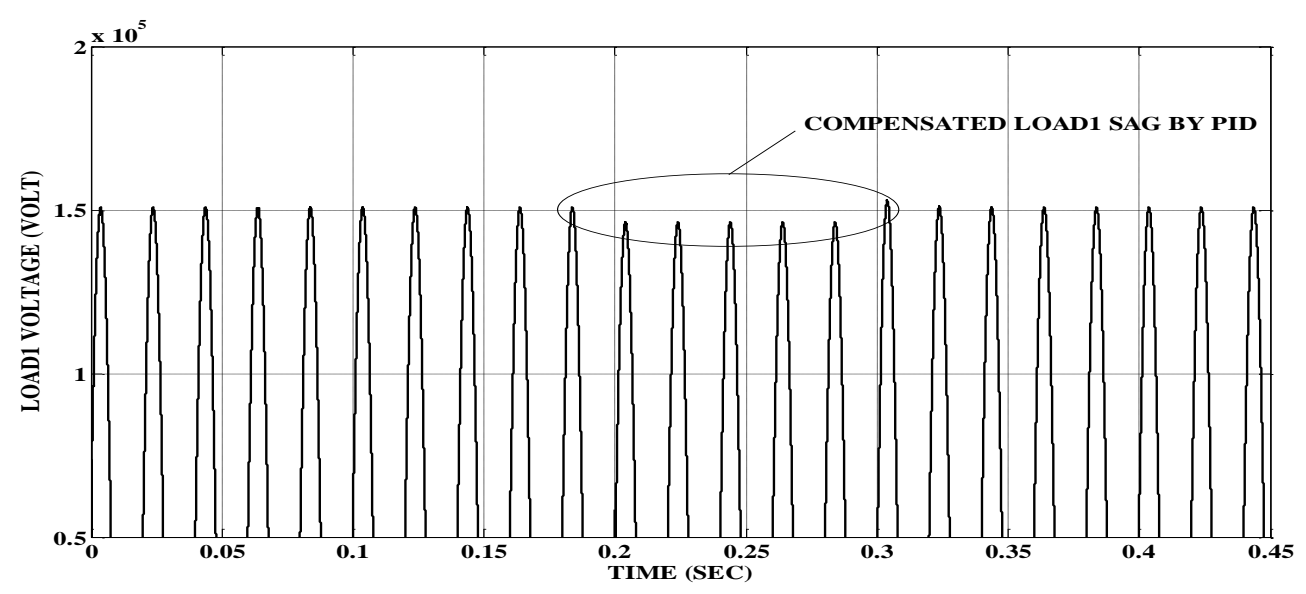

Figure 9.d. Compensated Load1 Voltage using PID Controller

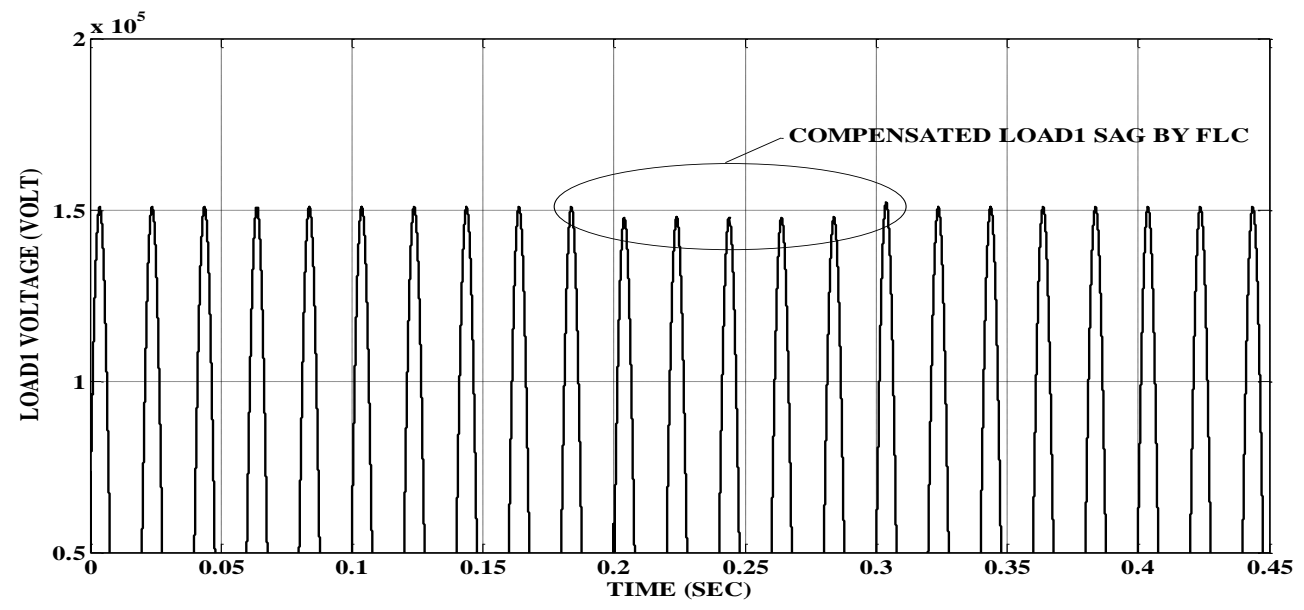

Figure 9.e. Compensated Load1 Voltage using Fuzzy Logic Controller

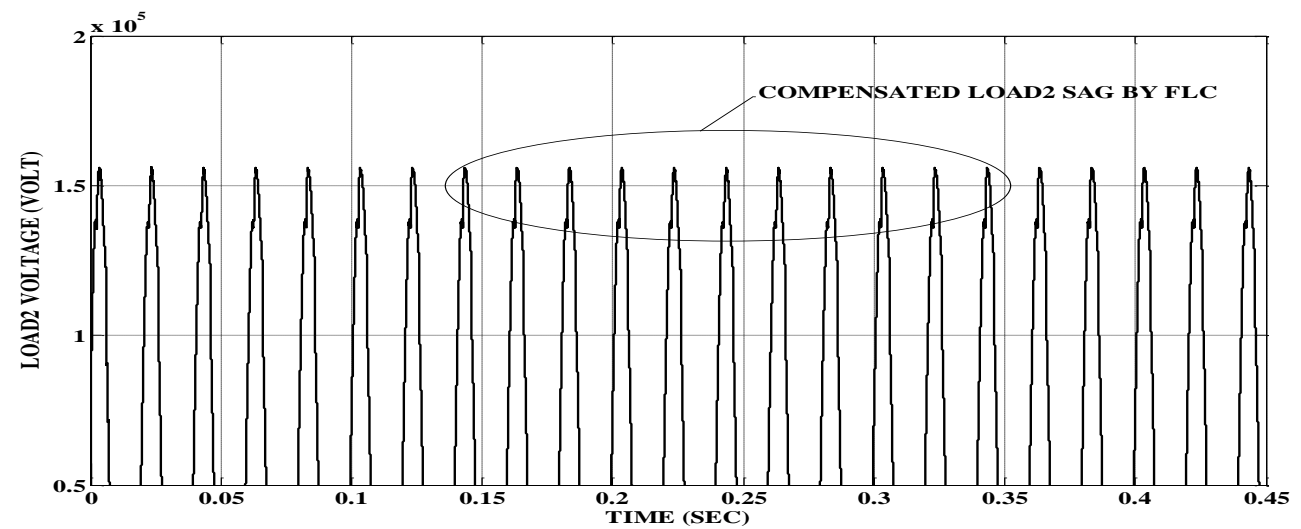

Figure 9.f. Compensated Load2 Voltage using Fuzzy Logic controller Figure 9. Various Voltages during Sag 
Figure 9 shows the source voltage, uncompensated load voltage with sag, compensated load 1 voltage $\mathrm{V}_{11}$ and Load 2 voltage in single phase using PI, PID and Fuzzy logic controller

Figure 9.a. shows the source voltage. The sag in the load voltage is caused by a sudden rise in the load and it is shown in Figure 9.b. This is reduced by the DC link voltage controller in MC-UPQC. Compensated load 1 voltage by PI, PID and FLC are shown in Figure 9.c, Figure 9.d and Figure 9.e. Figure 9.f shows the compensated load 2 voltage $V_{12}$ by FLC.

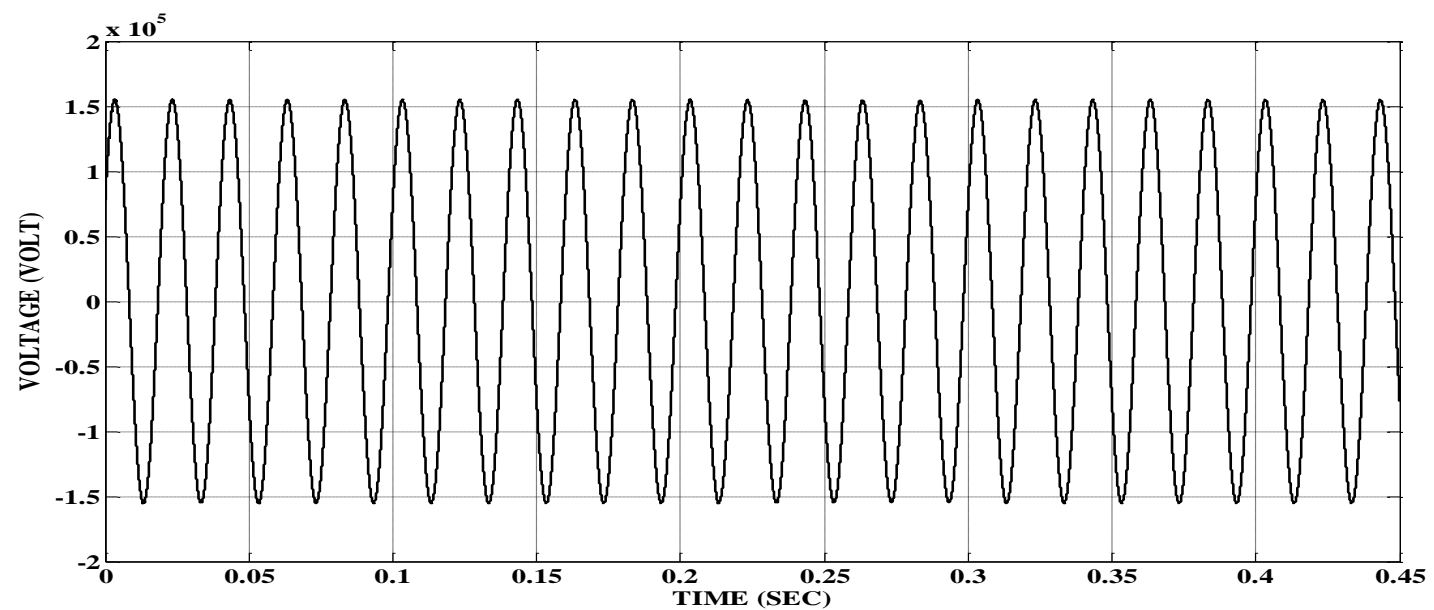

Figure 10.a. The Source Voltage

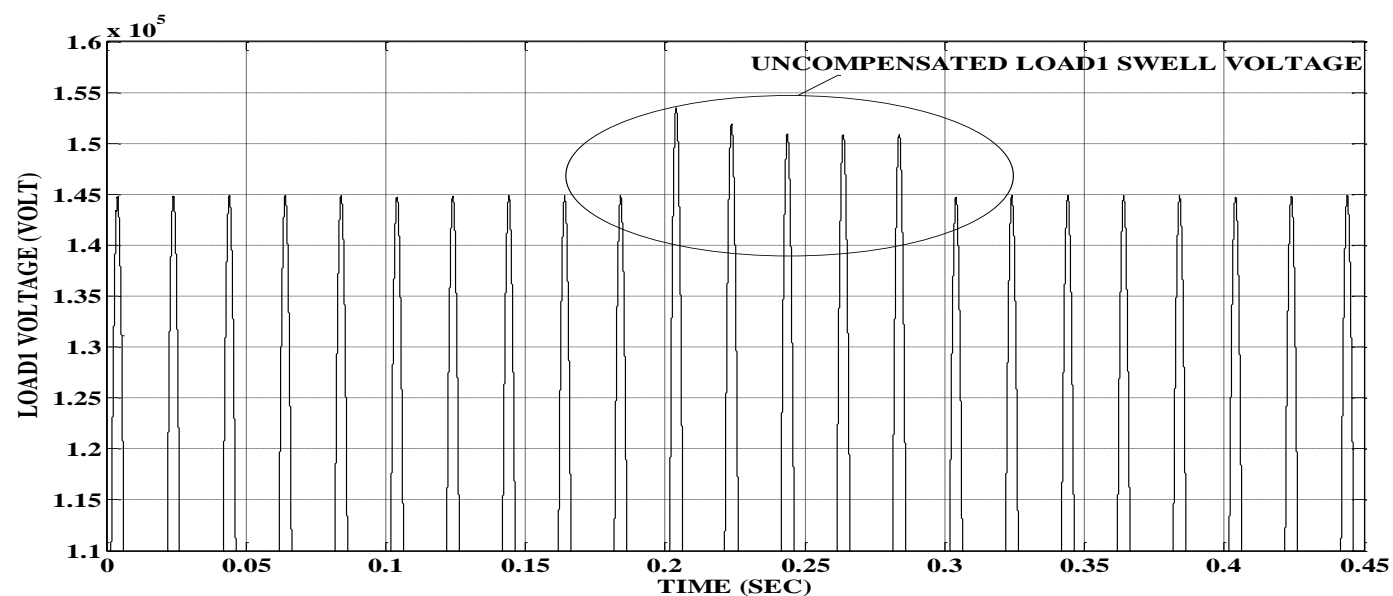

Figure 10.b. Uncompensated Load1 Voltage 


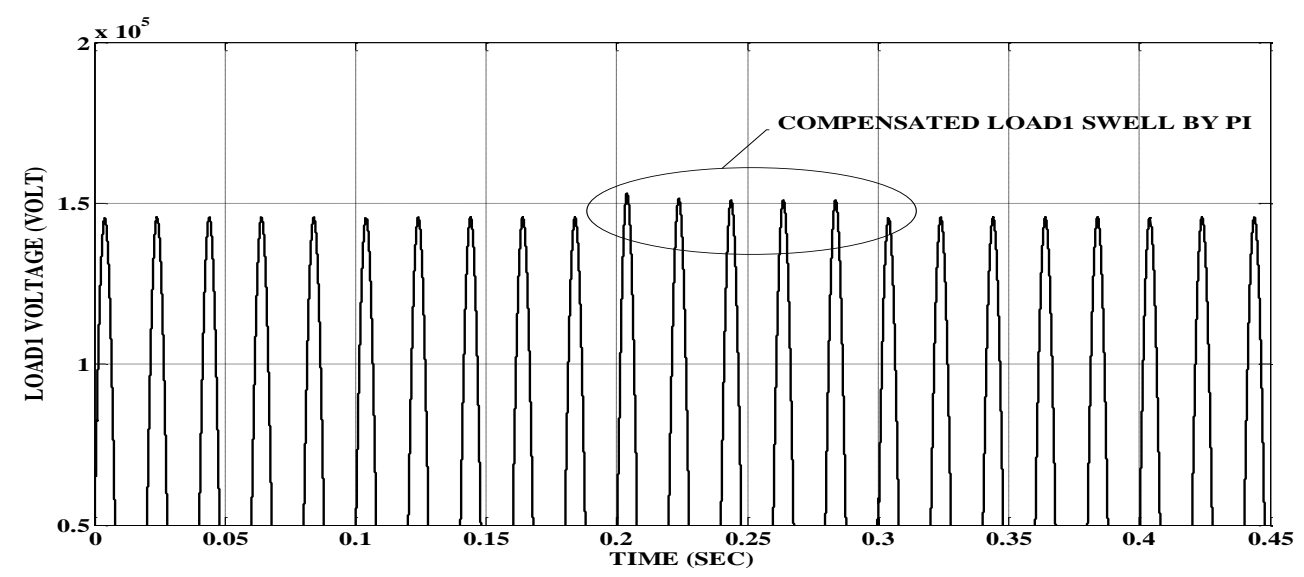

Figure 10.c. Compensated Load1 Voltage using PI Controller

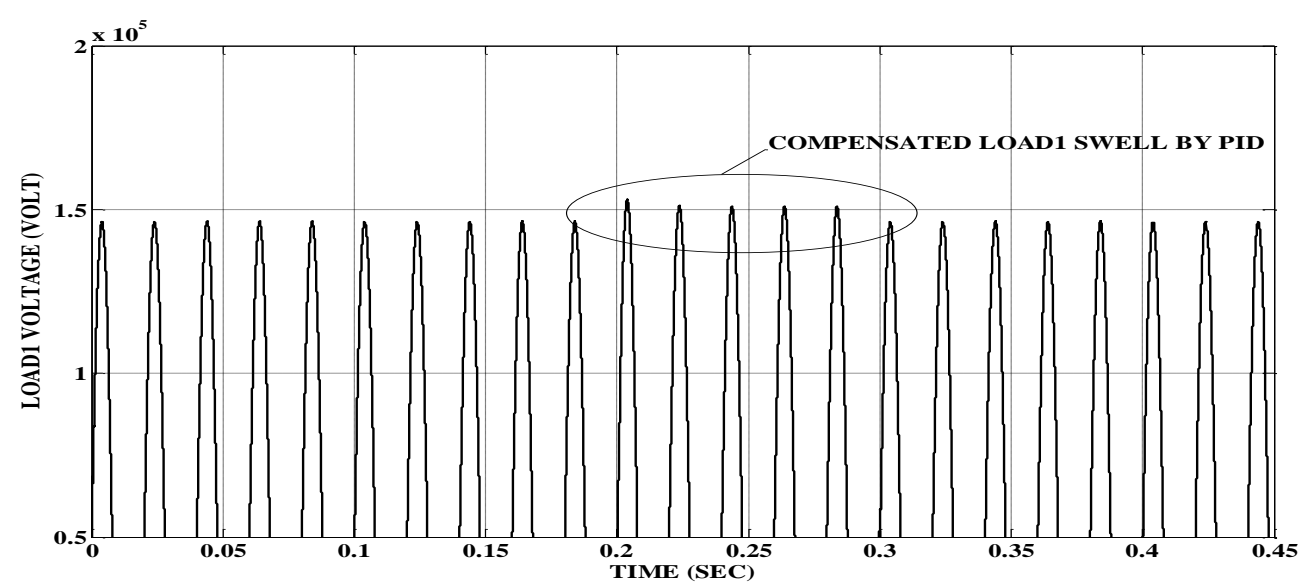

Figure 10.d. Compensated Load1 Voltage using PID Controller

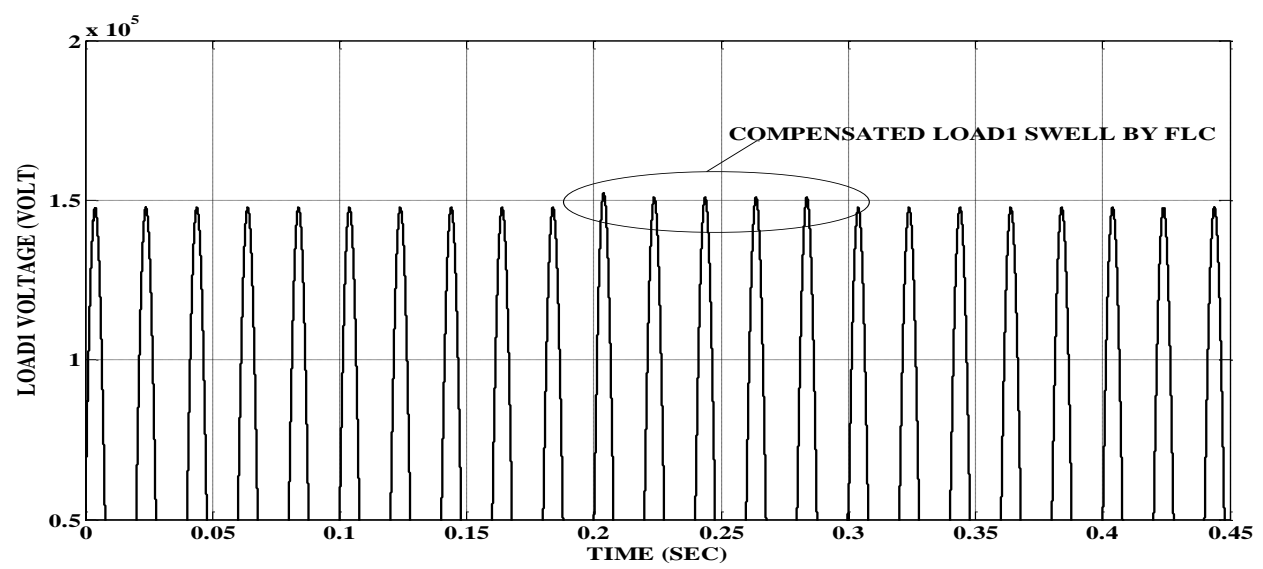

Figure 10.e. Compensated Load1 Voltage using Fuzzy Logic Controller 


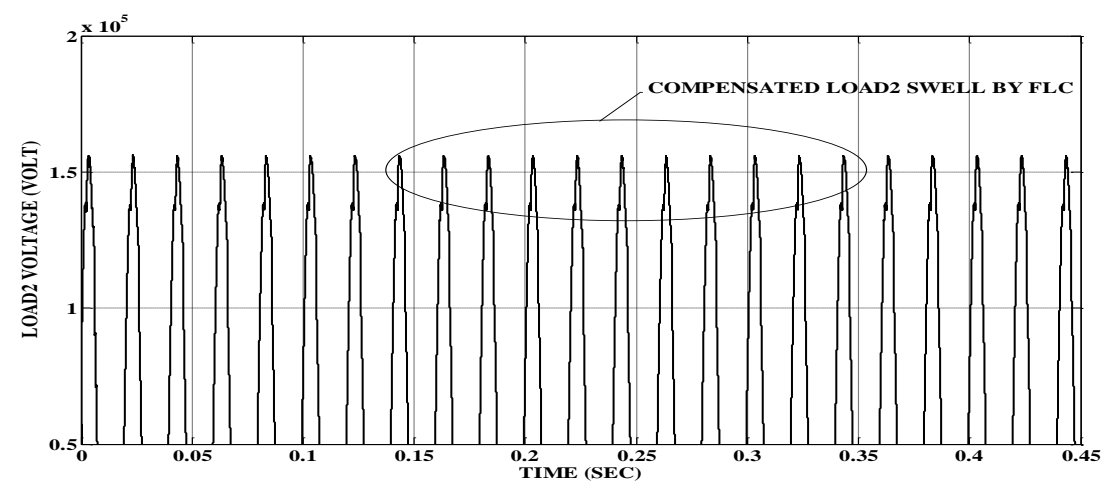

\section{Figure 10.f. Compensated Load2 Voltage using Fuzzy Logic Controller Figure 10. Various Voltages during Swell}

Figure 10 The source voltage, uncompensated load voltage with sag, compensated load 1 voltage $\mathrm{V}_{11}$ and Load 2 voltage in three phase using PI, PID and Fuzzy logic controller

Figure 10.a shows the source voltage. The swell in a load voltage caused by a sudden drop in the load is shown Figure 10.b. This is reduced by the DC link voltage controller in MC-UPQC. Compensated load 1 voltage by PI, PID and FLC are shown in Figure 10. c. Figure 10. $d$ and Figure 10. e. Figure 10.f shows the compensated load 2 voltage $V_{12}$ by FLC.

The series compensators of MC-UPQC compensates voltage oscillations during all voltage related problems such as voltage sag/swell, voltage harmonics etc. The effectiveness of PI based MC-UPQC is evident from the above simulations. The THD of load voltage before compensation is observed at $27.19 \%$. After compensation the THD in a load voltage observed is $3.45 \%$ which satisfies the standard of IEEE .Thus a significant improvement in the frequency spectrum and THD after compensation is clearly demonstrated by PI,PID based MC-UPQC is shown in Figure11 and Figure 12. Voltage quality is yet to be improved which is enhanced using FLC. Figure 13 Shows the Total Harmonic Distortion in a load voltage compensated by FLC based MC-UPQC is $1.21 \%$. Application of FLC in MC-UPQC reduces the THD than PI controller.

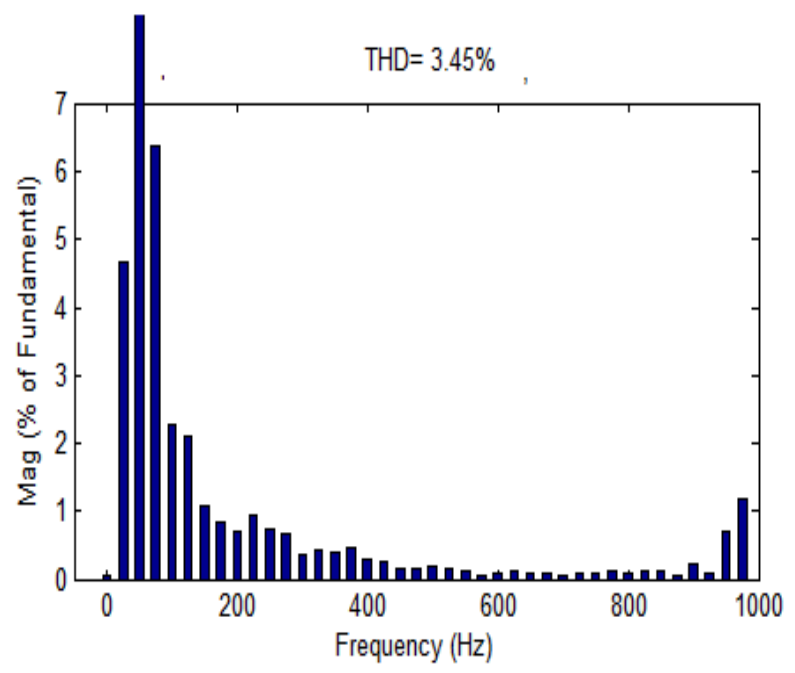

Figure 11. THD in Compensated Voltage using PI Controller 


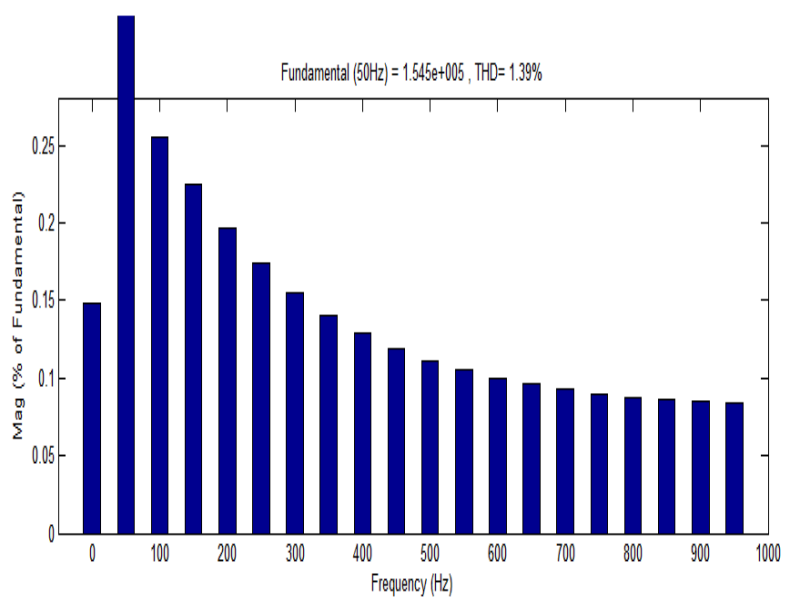

Figure 12. THD in Compensated Voltage using PID Controller

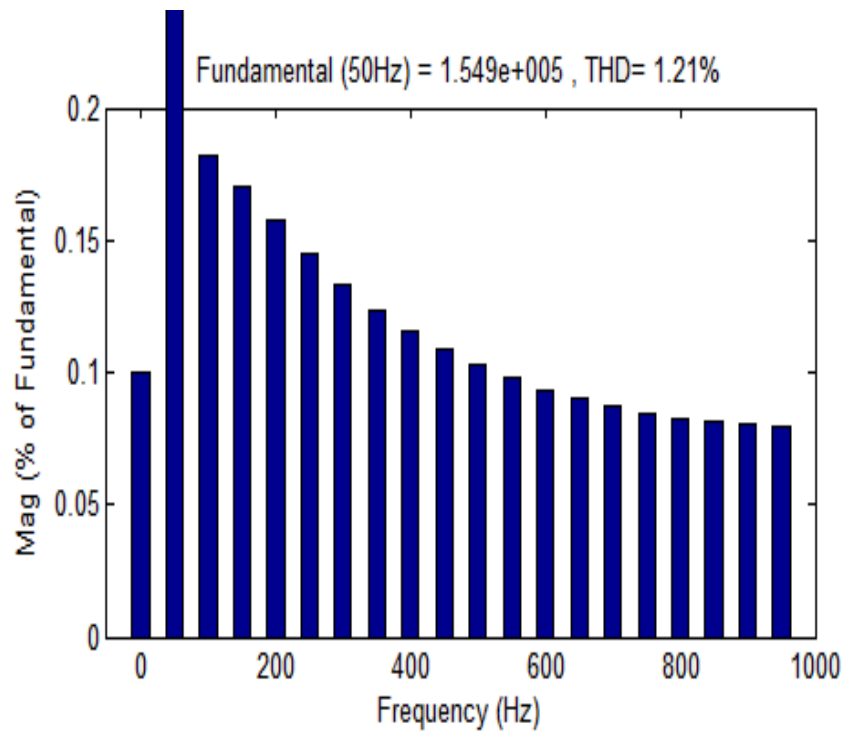

Figure 13. THD in Compensated Voltage using Fuzzy Logic Controller

The Table 3 shows the performance comparison of MC-UPQC based on PI, PID and Fuzzy Logic Controllers used as DC link voltage controllers.

Table 3. Performance Comparison of DC Link Voltage Controllers

\begin{tabular}{|c|c|c|c|}
\hline Controller & $\begin{array}{c}\text { THD in compensated } \\
\text { voltage in \% }\end{array}$ & $\begin{array}{c}\text { Lag in Compensated } \\
\text { Voltage Sag in \% }\end{array}$ & $\begin{array}{c}\text { Lag in Compensated } \\
\text { Voltage Swell in \% }\end{array}$ \\
\hline PI & 3.45 & 2.31 & 6.57 \\
\hline PID & 1.39 & 0.99 & 2.71 \\
\hline FLC & 1.21 & 0.67 & 0.77 \\
\hline
\end{tabular}




\section{Conclusions}

The MC-UPQC is used in the secondary power distribution side of the electrical network. In the existing system the MC-UPQC are placed only in the individual feeder of secondary power distribution side. In the proposed method a new approach is made by placing the MC-UPQC in sub transmission line of the electrical network with primary power distribution substations at the end with dual feeds. The primary power distribution substations are considered as load in the proposed system which is connected with many secondary power distribution substations. Several connected different feeders from the primary power distribution substation are benefited by this method. In this paper MCUPQC is proposed with a fuzzy logic controller in the sub transmission lines because of its increased speed of response. The entire system is analyzed with PI, PID and FLC based MC-UPQC using MATLAB7.7/Simulink under various load conditions. The proposed system improves the quality of power in two buses with sub transmission lines by avoiding the voltage sag and swell. In addition to the above the Total Harmonic Distortion is also minimized to $3.45 \%$ by using a PI controller based MC-UPQC which is within the level mentioned by IEEE standards. The proposed FLC based MC- UPQC reduces THD at 1.21 less than PI controller. The FLC based system reduces sag and swell on the load voltage than PI and PID based MC-UPQC. Therefore FLC based MC-UPQC system maintains THD in IEEE standard with good quality power by providing constant voltage.

\section{References}

[1] A. Tekel and M. Tumay, "Unified Power Quality Conditioner: A Literature Survey", J. Electrical systems, (2011), pp. 122-130, 7-1.

[2] A. K. Jindal, A. Ghosh, and A. Joshi, 'Interline Unified Power Quality Conditioner', IEEE Transactions on Power Delivery, vol. 22, no. 1, (2007) January, pp. 364-372.

[3] M. Aredes, K. Heumann, and E. H. Watanabe, “A universal active power line conditioner", IEEE Trans. Power Del., vol. 13, no. 2, (1998) April, pp. 545-551.

[4] Basu, S. P. Das and G. K. Dubey, "Comparative evaluation of two models of UPQC for suitable interface toenhance power quality”, Elect. Power Syst. Res., (2007), pp. 821-830.

[5] H. Fujita and H. Akagi, "The unified power quality conditioner: The integration of series and shunt active filters", IEEE Trans. Power Electron., vol. 13, no. 2, (1998) March, pp. 315-322.

[6] Ghosh and G. Ledwich, "A unified power quality conditioner (UPQC) for simultaneous voltage and current compensation", Elect. Power Syst. Res., (2001), pp. 55-63.

[7] L. Gyugyi, K. K. Sen, and C. D. Schauder, "Interline power flow controller concept: A new approach to power flow management in transmission systems", IEEE Trans. Power Del., vol. 14, no. 3, (1999) July, pp. 1115-1123.

[8] H. R. Mohammadi, A. Y. Varjani, and H. Mokhtari, "Multi Converter Unified Power-Quality Conditioning System: MC-UPQC", IEEE Transactions on Power Delivery, vol. 24, no. 3, (2009) July.

[9] B. Han B. Bae, H. Kim, and S. Beck, "Combined Operation of Unified Power-Quality Conditioner with Distributed Generation”, IEEE Transactions on Power Delivery, vol. 21, no. 1, (2006) January, pp. 330338.

[10] M. Hu and H. Chen, "Modeling and controlling of the unified power quality compensator," in Proc. 5th Int.Conf. Advances in Power System Control, Operation and Management, Hong Kong, China, (2000), pp. 431-435.

[11] K. K. Singh and J. K Dwivedi, "Performance Study of Unified Power Quality Conditioner Using Matlab Simulink', International Journal of Scientific \& Technology Research, vol. 1, no. 11, (2012), December.

[12] M. Kesler and E. Ozdemir, "Simplified Control Method for Unified Power Quality Conditioner (UPQC)", International Conference on Renewable Energies and Power Quality, (2009), pp. 1-5.

[13] M. Forghani and S. Afsharnia, "Online Wavelet Transform-Based Control Strategy for UPQC Control System”, IEEE Transactions on Power Delivery, vol. 22, no. 1, (2007) January, pp. 481-491. 
[14] Mohankumar and Manoharan, "Performance analysis of multi converter unified power quality conditioner using PI controller", Australian Journal of Basics and Applied Sciences, (2013), pp. 331-340.

[15] B. Rajani and P. S. R. , "Pi \& Fuzzy Logic Controller Based Multi Converter Unified Power Quality Conditioner", International Journal of Engineering and Advanced Technology, vol. 1, no. 5, (2012), pp. 208-212.

[16] S. Chakraborty and M. G. Simoes, "Experimental Evaluation of Active Filtering in a Single-Phase HighFrequency AC Microgrid", IEEE Transactions On Energy conversion, vol. 24, no. 3, (2009), pp. 673682.

[17] V. G. Kinhal, P. Agarwal, and H. O. Gupta, "Performance Investigation of Neural-Network-Based Unified Power-Quality Conditioner", IEEE Transactions on Power Delivery, vol. 26, no. 1, (2011) January, pp. 431-437.

[18] V. Khadkikar, "Enhancing Electric Power Quality Using UPQC: A Comprehensive Overview", IEEE Transactions on Power Electronics, vol. 27, no. 5, (2012) May.

[19] N. H. Woodley, A. Sundaram, B. Coulter, and D. Morris, "Dynamic voltage restorer demonstration project experience," in Proc. 12th Conf. Elect. Power Supply IND., Pattaya, Thailand, (1998).

\section{Authors}

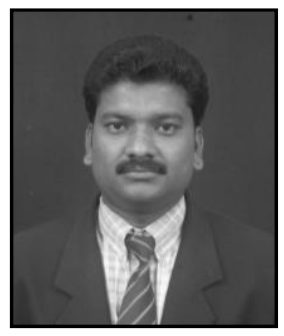

G. B. Mohankumar received his Bachelor of Engineering Degree in Electrical and Electronics Engineering from Bharathiyar University, Coimbatore, Tamilnadu, India in the year 2001, Master of Technology in Power Systems Engineering from The National Institute of Engineering, Mysore, Visvesvaraya Technological University, Karnataka, India in the year 2004 and pursuing Ph.D. in faculty of Electrical Engineering at Anna University, Chennai, Tamil Nadu, India. He has published two international journals and has six International/National conference publications. $\mathrm{He}$ is a life member of Indian Society for Technical Education and member of The Institution of Engineers (India). His research interest includes power system planning, operation and control, voltage stability analysis, FACTS Controllers and Artificial Intelligence applications to power systems.

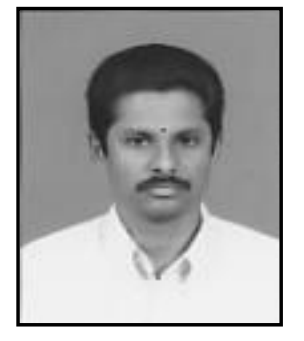

S. Manoharan took his B.E Degree in Electrical and Electronics Engineering from Bharathiyar University, Coimbatore, Tamilnadu, India in the year 1997, Master of Engineering in Electrical Machines from PSG College of Technology, Coimbatore in 2004 and Ph.D. in the area of Electrical Machines and Drives from Anna University, Chennai, TamilNadu,India.He has over 18 years of teaching experience. $\mathrm{He}$ is currently working as Professor and Head, Department of Electronics and Instrumentation Engineering in Karpagam College of Engineering, Coimbatore, Tamilnadu, India. He has published 20 research papers in both International and National Journals. He is a life member of ISTE, SSI and member of IE (India) and IEEE. 
International Journal of Control and Automation Vol.8, No.3 (2015) 